\title{
Gambaran pertumbuhan pada anak dengan penyakit jantung bawaan di RSUP Prof. Dr. R. D. Kandou Manado
}

\author{
${ }^{1}$ Natalia D. Kalalo \\ ${ }^{2}$ Vivekenanda Pateda \\ ${ }^{2}$ Praevillia Salendu
}

\author{
${ }^{1}$ Kandidat Skripsi Fakultas Kedokteran Universitas Sam Ratulangi Manado \\ ${ }^{2}$ Bagian Ilmu Kesehatan Anak Fakultas Kedokteran Universitas Sam Ratulangi Manado \\ Email: nataliakalalo@gmail.com
}

\begin{abstract}
Congenital heart disease (CHD) is the most common congenital anomaly and is the most common type of heart disease in children. CHD is also called a congenital heart defect, is a general term for structural abnormalities of the heart and great vessels that occurred at birth. Impaired growth is one of the complications of congenital heart disease. This study was aimed to determine the growth in children with congenital heart disease who were treated in the Division of Pediatric, Prof. Dr. R. D. Kandou Hospital Manado. This was a descriptive retrospective study analyzed with univariate data analysis. Samples were pediatric patients aged 1-5 years with a primary diagnosis of CHD in the Division of Pediatric, Prof. Dr. R. D. Kandou Hospital Manado from 2014 to 2016. Data were plotted into the $2006 \mathrm{WHO}$ growth curves (z-score). The results showed that there were 43 children with congenital heart disease, mostly males. Assessments of the growth based on W/A and $\mathrm{H} / \mathrm{A}$ showed that the majority of children had normal growth. Based on the W/H and BMI/A, it was found that the majority of children had good nutritional status.
\end{abstract}

Keywords: congenital heart disease, growth, child

\begin{abstract}
Abstrak: Penyakit jantung bawaan (PJB) merupakan kelainan kongenital yang paling umum dan sebagai jenis penyakit jantung tersering pada anak. PJB disebut juga defek jantung bawaan, merupakan istilah yang umum untuk kelainan struktur jantung dan pembuluh darah besar yang muncul sejak lahir. Gangguan pertumbuhan merupakan salah satu komplikasi dari penyakit jantung bawaan. Tujuan penelitian ini adalah untuk mengetahui pertumbuhan pada anak dengan PJB yang dirawat di bagian Ilmu Kesehatan Anak RSUP Prof. Dr. R. D. Kandou Manado. Penelitian yang dilaksanakan bersifat deskriptif retrospektif dengan analisis data univariat. Sampel penelitian ini adalah pasien anak usia 1-5 tahun dengan diagnosis utama PJB yang dirawat di bagian Ilmu Kesehatan Anak RSUP Prof. Dr. R. D. Kandou Manado pada Periode tahun 2014-tahun 2016. Analisis data penelitian menggunakan kurva WHO 2006 (z-score). Dari hasil peneltian didapat 43 orang anak dengan PJB, terbanyak pada anak laki-laki. Gambaran pertumbuhan berdasarkan BB/U dan $\mathrm{TB} / \mathrm{U}$ didapatkan mayoritas anak dengan status gizi normal. Berdasarkan BB/TB dan IMT/U, didapatkan mayoritas anak dengan status gizi baik.

Kata kunci: penyakit jantung bawaan, pertumbuhan, anak
\end{abstract}

Penyakit jantung bawaan (PJB) merupakan kelainan kongenital yang paling umum dan sebagai jenis penyakit jantung tersering pada anak. ${ }^{1}$ PJB disebut juga defek jantung bawaan, merupakan istilah yang umum untuk kelainan struktur jantung dan pembuluh darah besar yang muncul sejak lahir. $^{2}$

Penyakit jantung bawaan dapat diklasifikasikan menjadi 2 kelompok, yakni 
penyakit jantung bawaan non-sianotik dan sianotik. ${ }^{3}$ Pada penyakit jantung bawaan non-sianotik mencakup lesi dengan pirau kiri ke kanan yang menyebabkan peningkatan aliran darah pulmonal (duktus arteriosus paten atau patent ductus arteriosus), defek septum ventrikel atau ventricular septal defect (VSD), defek septum arium atau atrial septal defect (ASD), dan lesi obstruktif (stenosis aortic, stenosis pulmonal, koarktasio aorta), yang umumnya disertai aliran darah pulmnal yang normal. ${ }^{4}$ Pada penyakit jantung bawaan sianotik terjadi dikarenakan sebagian aliran darah balik sistemik dari jantung kanan ke jantung kiri dan kembali ke seluruh tubuh tanpa melalui paru terlebih dahulu (lesi pirau kanan ke kiri). Kelompok ini paling sering dijumpai yaitu tetralogy fallot, transposisi arteri besar, atresia tricuspid, trunkus arteriosus, total anomalous pulmonary venous return. ${ }^{4}$

Di Eropa, prevalensi total kelahiran penyakit jantung bawaan adalah 8,2 per 1000 kelahiran hidup yang lebih tinggi dari prevalensi kelahiran hidup yang dilaporkan di Amerika Serikat (6,9 per 1000 kelahiran hidup). ${ }^{5}$

Penyakit jantung bawaan pada anak di Indonesia cukup banyak, dimana sekitar 6 sampai 10 dari 1000 bayi lahir, mengidap PJB. Sekitar 2-5 persen kelainan ini erat kaitannya dengan abnormalitas kromosom. Misalnya pada penderita sindrom Down, sekitar $60 \%$ selalu disertai kelainan jantung kongenital seperti defek septum ventrikel, tetralogi fallot, duktus arteriosus persisten, dan defek septum atrium. ${ }^{6}$ Penelitian dari Maramis et al. ${ }^{3}$ di RSUP Prof. Dr. R. D Kandou Manado menunjuk-kan 53 anak penderita PJB, dimana yang terbanyak berumur 1-6 tahun. Jenis PJB terbanyak ialah ASD (34\%) dan VSD (28,3\%).

Pertumbuhan merupakan bertambahnya jumlah dan besarnya sel di seluruh bagian tubuh secara kuantitatif dapat diukur atau ditandai dengan adanya peningkatan dalam berat atau ukuran dari seluruh/ sebagian organ. Pertumbuhan yang normal sangat dipengaruhi oleh berbagai faktor, diantaranya faktor endokrin, lingkungan, nutrisi, dan genetik. Pola pertumbuhan linier yang normal merupakan bukti nyata dari kesehatan yang menyeluruh dan sebagai parameter kesejahteraan anak. ${ }^{4}$

Gangguan pertumbuhan merupakan salah satu komplikasi dari penyakit jantung bawaan. Beberapa studi menunjukan adanya hubungan antara PJB dengan pertumbuhan pada anak.

Penelitian ini bertujuan untuk mengetahui gambaran pertumbuhan pada anak dengan PJB di Bagian lmu Kesehatan Anak RSUP Prof. Dr. R. D. Kandou Manado.

\section{METODE PENELITIAN}

Jenis penelitian yang dilaksanakan ialah deskriptif retrospektif dengan analisis data univariat. Sampel penelitian ialah pasien anak yang didiagnosis PJB dan dirawat di Bagian Ilmu Kesehatan Anak RSUP Prof. Dr. R. D. Kandou Manado pada periode tahun 2014-2016. Pengambilan sampel menggunakan consecutive sampling. Kriteria inklusi penelitian ini ialah anak dengan diagnosis utama PJB usia 1-5 tahun. Jenis PJB yang diapakai, yaitu: PJB non-sianotik dan PJB sianotik

Analisis data penelitian menggunakan kurva pertumbuhan WHO 2006 (z-score) untuk anak usia $<5$ tahun yang terdiri dari:

a. Berat badan menurut usia

b. Tinggi badan menurut usia

c. Berat badan menurut tinggi badan

d. Indeks masa tubuh menurut usia

Data diperoleh dari rekam medik berupa diagnosis dan hasil pemeriksaan fisik pada pasien anak dengan PJB. Hasil penelitian disajikan dalam bentuk tabel distribusi frekuensi.

\section{HASIL PENELITIAN}

Tabel 1 memperlihatkan distribusi frekuensi berdasarkan tahun. Pada tahun 2014 terapat 7 kasus PJB (16.27\%); tahun 2015 terdapat 29 kasus PJB (67.44\%); dan tahun 2016 terdapat 7 kasus PJB (16.27\%). Jumlah keseluruhan pasien PJB berusia 1-5 tahun yang dirawat di Bagian Ilmu Kesehatan Anak RSUP Prof. Dr. R. D. 
Kandou Manado periode tahun 2014 tahun 2016 ialah 43 kasus.

Tabel 1. Distribusi Frekuensi Berdasarkan Tahun

\begin{tabular}{ccc}
\hline Tahun & N & $(\boldsymbol{\%})$ \\
\hline 2014 & 7 & 16,27 \\
2015 & 29 & 67,44 \\
2016 & 7 & 16,27 \\
\cline { 1 - 1 } Total & 43 & 100 \\
\hline
\end{tabular}

Pada Tabel 2 dapat dilihat jumlah pasien PJB yang berjenis kelamin laki-laki adalah 22 orang $(48.83 \%)$, dan jumlah pasien yang berjenis kelamin perempuan adalah 21 orang $(51.16 \%)$.

Tabel 2. Distribusi Pasien Anak Dengan PJB Berdasarkan Jenis Kelamin

\begin{tabular}{ccc}
\hline Jenis kelamin & $\mathbf{N}$ & $\mathbf{( \% )}$ \\
\hline Laki-Laki & 22 & 51,16 \\
Perempuan & 21 & 48,83 \\
Total & 43 & 100 \\
\hline
\end{tabular}

Tabel 3 memperlihatkan jumlah pasien berusia 1-2 tahun sebanyak 25 orang (58.13\%); yang berusia 3-4 tahun sebanyak 17 orang $(39.53 \%)$; dan yang berusia 5 tahun sebanyak 1 orang $(2.32 \%)$.

Tabel 3. Distribusi Frekuensi Berdasarkan Usia

\begin{tabular}{ccc}
\hline Usia & $\mathbf{N}$ & $\mathbf{( \% )}$ \\
\hline 1-2 tahun & 25 & 58,13 \\
3-4 tahun & 17 & 39,53 \\
5 tahun & 1 & 2,32 \\
\cline { 1 - 1 } Total & 43 & 100 \\
\hline
\end{tabular}

Pada Tabel 4 dapat dilihat distribusi frekuensi berdasarkan klasifikasi jenis PJB. Pasien dengan PJB non sianotik terdapat 37 orang $(86,04 \%)$ dan pasien dengan PJB sianotik ialah 6 orang $(13,95 \%)$.

Pasien dengan status gizi kurang 9 orang $(20.93 \%)$; status gizi baik sebanyak 32 orang $(74,41 \%)$; dan status gizi lebih sebanyak 2 orang $(4,65 \%)$ (Tabel 5$)$.

Pasien dengan status gizi pendek berjumlah 8 orang (18.60\%). Pasien dengan status gizi normal berjumlah 33 orang
(76.74\%). pasien dengan status gizi tinggi sebanyak 2 orang (4.65\%) (Tabel 6).

Tabel 4. Distribusi Frekuensi Berdasarkan Jenis PJB

\begin{tabular}{ccc}
\hline Jenis PJB & $\mathbf{n}$ & $\mathbf{( \% )}$ \\
\hline PJB nonsianotik ASD & 17 & 39.53 \\
VSD & 13 & 30.23 \\
PDA & 1 & 2.32 \\
AVSD & 1 & 2.32 \\
ASD+SP & 1 & 2.32 \\
ASD+PDA & 1 & 2.32 \\
VSD+PDA & 1 & 2.32 \\
ASD+VSD & 1 & 2.32 \\
PJB sianotik & & \\
TOF & 5 & 11.62 \\
AP+VSD & 1 & 2.32 \\
PJB asianotik & 37 & 86.04 \\
PJB sianotik & 6 & 13.95 \\
Total & 43 & 100 \\
\hline
\end{tabular}

Tabel 5. Distribusi Status Gizi Berdasarkan Berat Badan Menurut Usia

\begin{tabular}{ccc}
\hline Status Gizi & N & $(\mathbf{\% )}$ \\
\hline Gizi Kurang & 9 & 20.93 \\
Gizi Baik & 32 & 74.41 \\
Gizi Lebih & 2 & 4.65 \\
\cline { 1 - 1 } Total & 43 & 100 \\
\hline
\end{tabular}

Tabel 6. Distribusi Status Gizi Berdasarkan Tinggi Badan Menurut Usia

\begin{tabular}{cccc}
\hline Status Gizi & $\mathrm{n}$ & $(\%)$ \\
\hline Pendek & 8 & 18.60 \\
Normal & 33 & 74.74 \\
Tinggi & 2 & 4.65 \\
\cline { 1 - 1 } Total & 43 & 100 \\
\hline
\end{tabular}

Pasien dengan status gizi kurus berjumlah 6 orang (13.95\%). Terdapat 32 (74.41\%) orang dengan status gizi baik. Pasien dengan status gizi gemuk sebanyak 5 orang $(11.62 \%)$ (Tabel 7$)$.

Tabel 7. Distribusi Status Gizi Berdasarkan Berat Badan Menurut Tinggi Badan

\begin{tabular}{cccc}
\hline Status Gizi & & n & $(\boldsymbol{\%})$ \\
\hline Kurus & & 6 & 13.95 \\
Normal & & 32 & 74.41 \\
Gemuk & 5 & 11.62 \\
\cline { 1 - 1 } Total & 43 & 100 \\
\hline
\end{tabular}


Pada Tabel 8 anak dengan status gizi sangat kurus sebanyak 2 orang $(4.65 \%)$. Anak dengan status gizi kurus sebanyak 5 orang $(11.62 \%)$. Status gizi baik terdapat 30 orang $(69.76 \%)$. Pasien dengan status gizi gemuk sebanyak 6 orang $(13.95 \%)$.

Tabel 8. Distribusi Status Gizi Berdasarkan Indeks Massa Tubuh Menurut Usia

\begin{tabular}{ccc}
\hline Status Gizi & $\mathrm{n}$ & $(\%)$ \\
\hline Kurus & 7 & 16.27 \\
Normal & 30 & 69.76 \\
Gemuk & 6 & 13.95 \\
Total & 43 & 100 \\
\hline
\end{tabular}

Pada Tabel 9, yang dilaporkan dari $\mathrm{BB} / \mathrm{U}$ penderita dengan status gizi kurang, terdapat 5 orang dengan PJB non sianotik dan 4 orang dengan PJB sianotik. Status gizi baik, terdapat 30 orang dengan PJB non sianotik dan 3 orang dengan PJB sianotik. Pada status gizi lebih, terdapat 2 orang dengan PJB non sianotik dan tidak terdapat status gizi lebih pada PJB sianotik

Tabel 9. Distribusi Jenis PJB Berdasarkan Berat Badan Menurut Usia

\section{Jenis PJB}

\begin{tabular}{lccc} 
Status Gizi & $\begin{array}{c}\text { Non } \\
\text { sianotik }\end{array}$ & Sianotik & Total \\
\hline Gizi Kurang & 5 & 4 & 9 \\
Normal & 30 & 2 & 32 \\
Lebih & 2 & 0 & 2 \\
Total & 37 & 6 & 43 \\
\hline
\end{tabular}

Pada Tabel 10 dilaporkan bahwa penderita dengan status gizi pendek, terdapat 7 orang dengan PJB non sianotik dan 1 orang dengan PJB sianotik. Pada status gizi baik, didapatkan 28 orang dengan PJB non sianotik dan 5 orang dengan PJB sianotik. Status gizi tinggi, didapatkan 2 orang dengan PJB non sianotik dan tidak terdapat pada PJB sianotik.

Status gizi kurus, terdapat 3 orang dengan PJB non sianotik dan 3 orang dengan PJB sianotik. Status gisi kurus, terdapat 2 orang dengan PJB non sianotik dan 1 orang dengan PJB sianotik. Status gizi baik, terdapat 29 orang dengan PJB non sianotik dan 3 orang dengan PJB non sianotik. Status gemuk, terdapat 5 orang dengan PJB non sianotik dan tidak terdapat pada PJB sianotik (Tabel 11).

Tabel 10. Distribusi Jenis PJB Berdasarkan Tinggi Badan Menurut Usia

\begin{tabular}{lccc}
\hline & \multicolumn{2}{c}{ Jenis PJB } & \\
\cline { 2 - 3 } $\begin{array}{l}\text { Status } \\
\text { Gizi }\end{array}$ & $\begin{array}{c}\text { Non } \\
\text { sianotik }\end{array}$ & Sianotik & total \\
\hline Pendek & 7 & 1 & 8 \\
Normal & 28 & 5 & 33 \\
Tinggi & 2 & 0 & 2 \\
Total & 37 & 6 & 43 \\
\hline
\end{tabular}

Tabel 11. Distribusi Jenis PJB Berdasarkan Berat Badan Menurut Panjang Badan Atau Tinggi Badan

\begin{tabular}{lccc}
\hline \multirow{2}{*}{$\begin{array}{l}\text { Status } \\
\text { Gizi }\end{array}$} & \multicolumn{2}{c}{ Jenis PJB } & Non \\
\cline { 2 - 3 } & Sianotik & Sianotik & total \\
\hline Kurus & 3 & 3 & 6 \\
Normal & 29 & 3 & 32 \\
Gemuk & 5 & 0 & 5 \\
Total & 37 & 6 & 43 \\
\hline
\end{tabular}

Pada Tabel 12 dilaporkan bahwa penderita dengan tatus gizi kurus, terdapat 4 orang dengan PJB non sianotik dan 3 orang dengan PJB sianotik. Status gizi baik, terdapat 27 orang dengan PJB non sianotik dan 3 orang dengan PJB sianotik. Status gizi gemuk, terdapat 6 orang dengan PJB non sianotik dan tidak terdapat pada PJB sianotik.

Tabel 12. Distribusi Jenis PJB Berdasarkan Indeks Massa Tubuh Menurut usia

\begin{tabular}{lccc}
\hline \multirow{2}{*}{$\begin{array}{l}\text { Status } \\
\text { Gizi }\end{array}$} & $\begin{array}{c}\text { Non } \\
\text { sianotik }\end{array}$ & Sianotik & total \\
\hline Kurus & 4 & 3 & 7 \\
Normal & 27 & 3 & 30 \\
Gemuk & 6 & 0 & 6 \\
Total & 37 & 6 & 43 \\
\hline
\end{tabular}

Pada Tabel 13 dilaporkan bahwa 
penderita usia 1-2 tahun dilaporkan, terdapat 4 status gizi kurang, 20 orang dengan status gizi baik, 1 orang dengan status gizi lebih. Pada usia 3-4 tahun, terdapat 5 orang dengan status gizi kurang, 11 orang dengan status gizi baik, 1 orang dengan status gizi lebih. Pada usia 5 tahun, tidak terdapat pasien dengan status gizi kurang/lebih, terdapat 1 orang dengan status gizi normal.

Tabel 13. Distribusi Usia Pasien Berdasarkan Berat Badan Menurut Usia

\begin{tabular}{lcccc}
\hline Status & \multicolumn{3}{c}{ Usia } & \\
\cline { 2 - 4 } Gizi & $\begin{array}{c}\mathbf{1 - 2} \\
\text { tahun }\end{array}$ & $\begin{array}{c}\mathbf{3 - 4} \\
\text { tahun }\end{array}$ & $\begin{array}{c}\mathbf{5} \\
\text { tahun }\end{array}$ & Total \\
\hline Gizi & 4 & 5 & 0 & 9 \\
Kurang & & & & \\
Normal & 20 & 11 & 1 & 32 \\
Lebih & 1 & 1 & 0 & 2 \\
Total & 25 & 17 & 1 & 43 \\
\hline
\end{tabular}

Pada Tabel 14 dialaporkan bahwa penderit usia 1-2 tahun, terdapat 5 orang dengan status gizi pendek, 19 orang dengan status gizi baik, 1 orang dengan status gizi lebih. Usia 3-4 tahun, terdapat 2 orang dengan status gizi pendek, 14 orang dengan status gizi baik, 1 orang dengan status gizi tinggi. Usia 5 tahun, tidak terdapat pasien dengan status gizi normal/tinggi, terdapat 1 orang dengan status gizi pendek.

Tabel 14. Distribusi Usia Pasien Berdasarkan Tinggi Badan Menurut Usia

\begin{tabular}{lcccc}
\hline & \multicolumn{3}{c}{ Usia } & \\
\cline { 2 - 4 } $\begin{array}{l}\text { Status } \\
\text { Gizi }\end{array}$ & $\begin{array}{c}\mathbf{1 - 2} \\
\text { tahun }\end{array}$ & $\begin{array}{c}\mathbf{3 - 4} \\
\text { tahun }\end{array}$ & $\begin{array}{c}\mathbf{5} \\
\text { tahun }\end{array}$ & Total \\
\hline Pendek & 5 & 2 & 1 & 8 \\
Normal & 19 & 14 & 0 & 33 \\
Tinggi & 1 & 1 & 0 & 2 \\
Total & 25 & 17 & 1 & 43 \\
\hline
\end{tabular}

Pada Tabel 15 dialaporkan bahwa penderita usia 1-2 tahun, terdapat 3 orang dengan status gizi kurus, 19 orang dengan status gizi baik, 3 orang dengan status gizi gemuk. Usia 3-4 tahun, terdapat 3 orang dengan status gizi kurus, 12 orang dengan status gizi baik, 2 orang dengan status gizi lebih. Usia 5 tahun, terdapat 1 orang dengan status gizi baik, tidak terdapat pasien dengan status gizi kurus/lebih.

Tabel 15. Distribusi Usia Pasien Berdasarkan Berat Badan Menurut Tinggi Badan

\begin{tabular}{lcccc}
\hline Status & \multicolumn{3}{c}{ Usia } & \\
\cline { 2 - 4 } Gizi & $\begin{array}{c}\mathbf{1 - 2} \\
\text { tahun }\end{array}$ & $\begin{array}{c}\mathbf{3 - 4} \\
\text { tahun }\end{array}$ & $\begin{array}{c}\mathbf{5} \\
\text { tahun }\end{array}$ & Total \\
\hline Kurus & 3 & 3 & 0 & 6 \\
Normal & 19 & 12 & 1 & 32 \\
Gemuk & 3 & 2 & 0 & 5 \\
Total & 25 & 17 & 1 & 43 \\
\hline
\end{tabular}

Pada Tabel 16 dialaporkan bahwa penderita usia 1-2 tahun, terdapat 3 orang dengan status gizi kurus, 18 orang dengan status gizi baik, 4 orang dengan status gizi lebih. Usia 3-4 tahun, terdapat 4 orang dengan status gizi kurus, 11 orang dengan status gizi baik, 2 orang dengan status gizi lebih. Usia 5 tahun, terdapat 1 orang dengan status gizi baik, tidak terdapat pasien dengan status gizi kurus/lebih.

Tabel 16. Distribusi Usia Pasien Berdasarkan Indeks Massa Tubuh Menurut Usia

\begin{tabular}{lcccc}
\hline & \multicolumn{3}{c}{ Usia } & \\
\cline { 2 - 4 } Status & $\begin{array}{c}\mathbf{1 - 2} \\
\text { tahun }\end{array}$ & $\begin{array}{c}\mathbf{3 - 4} \\
\text { tahun }\end{array}$ & $\begin{array}{c}\mathbf{5} \\
\text { tahun }\end{array}$ & total \\
\hline Kurus & 3 & 4 & 0 & 7 \\
Normal & 18 & 11 & 1 & 30 \\
Gemuk & 4 & 2 & 0 & 6 \\
Total & 25 & 17 & 1 & 43 \\
\hline
\end{tabular}

\section{BAHASAN}

Berdasarkan data dari penelitian yang diperoleh melalui pengambilan data rekam medik menunjukkan pasien berusia $1-5$ tahun pada periode tahun 2014 sampai tahun 2016 dibagian Ilmu Kesehatan Anak RSUP Prof. DR. R. D. Kandou Manado adalah sebanyak 43 orang.

Dari data yang diperoleh, jumlah kasus dari tahun 2014 sampai tahun 2015 mengalami peningkatan. Pada tahun 2016, jumlah kasus menurun.

Berdasarkan jenis kelamin, pasien perempuan berjumlah lebih banyak dari perempuan, hal ini sesuai dengan penelitian 
oleh Marelli $\mathrm{dkk}^{20}$ yang menyatakan bahwa pasien yang menderita PJB lebih banyak perempuan dibandingkan laki-laki.

Berdasarkan kelompok umur, angka kejadian tertinggi pasien anak PJB terdapat pada kelompok umur 1-2 tahun. Hasil ini tidak jauh berbeda dengan penelitian oleh Hariyanto yang menyatakan bahwa umur paling banyak dengan PJB berusia 0-2 tahun. Penelitian Bhandari $\mathrm{dkk}^{22}$ juga menunjukan usia pasien terbesar adalah 0-1 tahun. Hal tersebut menunjukkan hampir semua pasien telah dapat dideteksi secara adekuat pada masa bayi.

Pada kelompok usia 1-2 tahun didapatkan mayoritas pasien mempunyai status gizi normal berdasarkan penilaian berat badan menurut usia, tinggi badan menurut usia. Pada penilaian berat badan menurut tinggi badan serta Indeks Massa Tubuh menurut usia didapatkan jumlah pasien terbanyak mempunyai status gizi baik.

Pada usia 3-4 tahun didapatkan mayoritas pasien dengan berstatus gizi baik pada penilaian berat badan menurut usia dan tinggi badan menurut usia, berat badan menurut tinggi badan serta Indeks Massa Tubuh menurut usia. Pada usia 5 tahun didapatkan status gizi baik pada penilaian berat badan menurut usia, berat badan menurut tinggi badan, dan Indeks Massa Tubuh menurut usia. Namun pada penilaian tinggi badan menurut usia didapatkan status gizi pendek.

Berdasarkan klasifikasi PJB, pasien dengan PJB non sianotik lebih banyak dari PJB sianotik. Dan mayoritas jenis PJB non sianotik yang didapat adalah ASD diikuti VSD. Hasil ini sesuai dengan peneletian oleh Maramis dkk ${ }^{3}$ anak dengan PJB non sianotik jenis ASD adalah yang terbanyak $(34,0 \%)$ dan diikuti oleh jenis VSD $(28,3 \%)$. Tidak berbeda jauh dengan penelitian Venugopalan $\mathrm{dkk}^{21}$ dalam hasilnya menyatakan bahwa anak dengan PJB nonsianotik jenis VSD terbanyak dan diikuti oleh jenis ASD.

Pada penderita PJB non sianotik ditemukan gambaran pertumbuhan secara keseluruhan berstatus gizi baik. Demikian juga pada PJB sianotik, ditemukan mayoritas berstatus gizi baik. Akan tetapi pada PJB sianotik tidak ditemukan pasien yang berstatus gizi lebih. Biasanya pasien dengan PJB sianotik mengalami keterlambatan pertumbuhan yang lebih parah dari pasien PJB nonsianotik. ${ }^{23}$ Pasien dengan PJB sianotik biasanya menunjukkan berat badan dan tinggi badan yang kurang dari anak seusianya. ${ }^{24}$

Gambaran pertumbuhan pasien yang didapatkan berdasarkan penilaian berat badan menurut usia terbanyak pada status gizi normal yaitu 32 pasien (74.41\%). Pada penilaian tinggi badan menurut usia jumlah pasien terbanyak juga pada status gizi normal 33 pasien (76.74\%). Berdasarkan penilaian berat badan menurut tinggi badan, ditemukan gambaran pertumbuhan terbanyak pada status gizi normal sebanyak 32 pasien $(74.41 \%)$. Serta gambaran pertumbuhan berdasarkan indeks massa ditemukan terbanyak pada status gizi normal sebanyak 30 pasien $(69.76 \%)$. Hasil ini berbeda dengan penelitian sebelumnya oleh Maramis $\mathrm{dkk}^{3}$ yang melaporkan bahwa anak dengan status gizi kurang adalah yang paling banyak.

\section{SIMPULAN}

Berdasarkan hasil penelitian dapat disimpulkan bahwa gambaran status gizi pertumbuhan pada anak dengan PJB di RSUP Prof. Dr. R. D. Kandou Manado secara umum didapatkan status gizi normal.

\section{SARAN}

1. Asupan makanan yang baik dan seimbang perlu diberikan pada anak dengan penyakit jantung bawaan.

2. Status gizi pada anak dengan penyakit jantung bawaan sangat diperlukam perhatian baik oleh orang tua pasien maupun oleh petugas medis.

3. Perlunya perhatian orang tua terhadap asupan gizi dan pemantauan pertumbuhan anak dengan Penyakit Jantung Bawaan

\section{DAFTAR PUSTAKA}

1. Hariyanto D. Profil Penyakit Jantung 
Bawaan di Instalasi Rawat Inap Anak RSUP Dr. M. Djamil Padang Januari 2008 - Februari 2011, Sari Pediatri, 2012:14:3

2. Ain N, Hariyanto D, Rusdan S. Karakteristik Penderita Penyakit Jantung Bawaan pada Anak di RSUP Dr. Djamil Padang Periode Januari 2010 - Mei 2012, Jurnal Kesehatan Andalas, 2015:4:3

3. Maramis $\mathbf{P}$, Kaunang $\mathbf{D}$, Rompis $\mathbf{J}$. Hubungan Penyakit Jantung Bawaan Dengan Status Gizi Pada Anak di RSUP Prof. Dr. R. D. Kandou Manao Tahun 2009-2013, Jurnal e-CliniC (eCl), 2014:2:2

4. Marcdante $K$, Kliegman $R$, Jenson $H$, Behrman R. Dalam NELSON Ilmu Kesehatan Anak Esensial Edisi Keenam, SAUNDERSR ELSEVIER, Indonesia, 2014: h.572-581

5. Konings DE, Slager $M$, Witsenburg $M$, Helbing W, et al. Birth Prevalence of Congenital Heart Disease Worldwide, American College Of Cardiology, 2011: 58: 21

6. Primasari D. Perbedaan Perkembangan Pada Anak dengan Penyakit Jantung Bawaan Sianotik dan Nonsianotik.(diakses 20 agustus 2016) available from :http://download.portalgaruda.org/arti cle.php?article $=73680 \& v a l=4695$

7. Syarif D, Anggriawan S, Putra S, Djer M, Anthropometric Profiles of Children With Congenital Heart Disease, Division of Pediatric Nutrition and Metabolic Disease,Departement of Child Health, University of Indonesia, 2011.Jakarta;20:1

8. Blue G, Kirk E, Sholler G, Harvey R, Winlaw D, Congenital heart disease: current about causes and inheritance, Departement Of Medical Genetics, Sydney Children's Hospital, Victor Chang Cardiac Research Institute,MJA 2012: 197: 155-159

9. Dida, Maya. Pengantar Ilmu Kesehatan Anak. D-MEDIKA (Anggota IKAPI). No. 325-B. Jogjakarta: 2012: h:20-23

10.Soetjiningsih. Tumbuh Kembang Anak, EGC. Jakarta : 1995. h: 2-8

11.Ariani, Yosoprawoto M. Children Age and Mother Literacy as the Risk Factor for Children Developmen Disorder,
Jurnal Kedokteran Brawijaya, 2012

12.Abraham, Hoffman J, Rudolph C. Buku Ajar Pediatri RUDOLPH (edisi 20)

Vol 1, EGC. Jakarta: h: 3-12

13.Gunawan G, Fadlyana e, Rusmil $K$. Hubungan Status Gizi dan Perkembangan Anak Usia 1-2 Tahun, Sari Pediatri, 2011: 13:2

14.UKK Nutrisi dan Penyakit Metabolik, Asuhan Nutrisi

Pediatrik,IDAI:Jakarta:2011[diakses

27 Agustus 2016] available from :http//www.idai.or.id/wpcontent/uplo ads/2013/02/Rekomendasi-

IDAI_Asuhan-Nutrisi-PediatrikPdf

15.Depkes RI 2011. Standar Antropometri Penilaian Status Gizi Anak. Jakarta : Departemen Kesehatan Republik Indonesia

16.Daymont C, Neal A, Prosnitz A, Cohen M., Growth in Children With Congenital Heart Disease, Pediatrics, 2013.

17.Al-Asy H, Donia A, El-Amrosy D, Rabee E, Bendary A. The Levels of Ghrelin in Children with Cyanotic and Acyanotic Congenital Heart Disease, Pediatric 2014;6:e209

18.Eren E, Papatya E, Bostan O, Saglam H, Tarim O, Evaluation of Endocrine Function in Pediatric With Cyanotic Congenital Heart Disease, Biomedical Research 2013;24:1:7781

19.WHO, Growth Child Standard. World Healthy Organization [diakses 7 September 2016]. Available from :http://www.who.int/childgrowth/stan dards/chart_catalogue/en/

20.Marelli A, Mackie A, Ionescu R, Rahme E, Pilote L. Congenital Heart Disease in the General Population: Changing Prevalence and Age Distribution, American Heart Association, 2007;115:163-172

21. Venugopalan $P$, Akinbani $F$, Khalid $M$, Ajit K. Malnutrition in Children with Congental Heart Defect, Department of Child and the Department of Cardiology University Hospital Muscat of Oman, 2001;22:11

22.GS Shah, MK Singh, TR Pandey, BK Kalakheti, GP Bhandari. Incidence of congenital heart diseasein tertiary care of hospital. Kathmandu 
University Med J 2008;33-6

23.Kumala E. Perbedaan Status Gizi Pada Anak Dengan Penyakit Jantung Bawaan Sianotik dan Nonsianotik. [cited 9 november 2016] available from :http://eprints.undip.ac.id/37513/1/EL IZABETH
24.Queen S, Kathy K. Cardiology. Pediatric Nutrition. Jones \& Bartlett Publisher; 2011 [cited 15 November 2016]. Available from http://books.google.co.id/books?id=J8 Xgyvr9038C\&pg=PA407\&hl=id\&so urce $=$ gbs_toc\&rcad $=4 \# v=$ onepage $\& \mathrm{q}$ $\& \mathrm{f}=$ false 